\title{
Fracture Mechanisms of Bone: A Comparative Study between Antler and Bovine Femur
}

\author{
P.Y. Chen ${ }^{1}$, F.A. Sheppard ${ }^{2}$, J.M. Curiel ${ }^{2}$, and J. McKittrick ${ }^{1,2}$ \\ ${ }^{1}$ Materials Science and Engineering Program, University of California, San Diego, La Jolla, CA \\ 92093-0418, U.S.A. \\ ${ }^{2}$ Department of Mechanical and Aerospace Engineering, University of California, San Diego, La \\ Jolla, CA 92093-0411, U.S.A.
}

\begin{abstract}
In this study, fracture toughness of North American elk (Cervus elaphus canadensis) antler and bovine femur were measured using four-point bending tests on single-edge notched compact samples (ASTM C1421). Tests were conducted on crack growth directions longitudinal and transverse to the long axis of antler and bone in both dry and hydrated conditions to study the effects of fiber orientation and hydration. Fracture toughness results in the transverse orientation were much higher than that in the longitudinal orientation and increased with degree of hydration for both antler and bovine femur. The fracture toughness of antler was $\sim 50 \%$ higher than that of bovine femur. The highest fracture toughness value was obtained from the hydrated antler in the transverse orientation, which reached $10.31 \mathrm{MPa} \cdot \mathrm{m}^{1 / 2}$ compared to that measured from bovine femur, which was $6.35 \mathrm{MPa} \cdot \mathrm{m}^{1 / 2}$. The crack propagation and fracture surface were characterized using scanning electron microscopy. Toughening mechanisms, including crack deflection by osteons, uncracked ligament bridging, and microcracks formation, were observed and discussed. Comparisons between antler and bone were made.
\end{abstract}

\section{INTRODUCTION}

Deer antlers, one of the fastest growing tissues in the animal kingdom, have a main function in intraspecific combat and have been designed for sustaining high impact loading and bending moment without fracture [1,2]. Antlers have a similar microstructure as mammalian long bones, composed primarily of type-I collagen fibrils and carbonated apatite crystals, arranged in osteons in the compact bone and a lamellar structure in the cancellous bone. However, there are distinct differences between antler and bone. First, antlers have lower mineral content ( $30 \mathrm{vol} \%)$ compared to bones ( $40 \mathrm{vol} \%)$ [3]. Secondly, antlers consist mainly of young primary osteons whereas most adult limb bones consist of secondary osteons and older interstitial bone [4].

There are limited reports on the mechanical properties of antlers [5-10]. Antler was found to have the lowest mineral content and consequently the lowest elastic modulus, roughly half that of the bovine femur [5]. Red deer antler had similar ultimate tensile strength as bovine femur, ranging between 100 and $140 \mathrm{MPa}$; however, the strain at failure (8-10\%) and work of fracture $\left(6186 \mathrm{~J} / \mathrm{m}^{2}\right)$ for antler were $4-5$ times greater than bovine femur [3]. Numerous studies on the fracture properties of bone were performed at various conditions, such as microstructure, orientation, hydration, strain rate, age, and diseases [11-19]. However, the fracture toughness of antler has not been studied. In the present work, we report the fracture toughness of elk antler and bovine femur and address the orientation and hydration effect on the fracture properties. The 
crack propagation and fracture surface were characterized under SEM and possible toughening mechanisms of antler were proposed.

\section{EXPERIMENTAL DETAILS}

Fully-grown antler from North American elk (Cervus elaphus canadensis) was obtained from a trading company (Into the Wild, WY, USA) and bovine femur was purchased from a local butcher. Samples from the compact region of antler and bovine femur were sectioned into rectangles ( $25 \mathrm{~mm}$ long, $4 \mathrm{~mm}$ wide and $3 \mathrm{~mm}$ thick) using a diamond saw. Notches were made using a $0.15 \mathrm{~mm}$ diameter wire saw and the notch length $\sim 1 \mathrm{~mm}$ was measured under optical microscope. Two equal sets of samples were prepared with the crack growth direction was either parallel (longitudinal or growth orientation) or perpendicular (transverse orientation) to the long axis of antler and bone. Samples in each orientation were tested in dry and hydrated conditions, which led to eight groups, as shown in Table I. Ten samples in each group were prepared, which resulted in total eighty samples. Re-hydration was accomplished by soaking samples in Hank's balanced salt solution (HBSS) for at least 24 hours. Quasi-static bending tests (strain rate $\sim 10^{-3}$ $\mathrm{sec}^{-1}$ ) were conducted on a universal testing machine (Instron 3346 Testing Systems, MA, USA) equipped with a lab-designed four-point bending fixture. Fracture toughness was calculated following the ASTM C1421 single-edged notched four-point bending method [20]. The fracture surface was characterized by a field emission scanning electron microscope (FEI-XL 30, FEI, OR, USA).

\section{DISCUSSION}

The cross-sectional microstructures in compact bone from antler and bovine femur are shown in Fig. 1(a) and (b), respectively. Osteons (Os), vascular channels (Va), Volkmann's canals (Vo), and lacunae spaces (L) can be observed in both antler and bovine femur. However, there are several distinguishable differences between the two. Antler consists mainly of primary osteons, which contain newly formed concentric lamellae surrounding vascular channels.

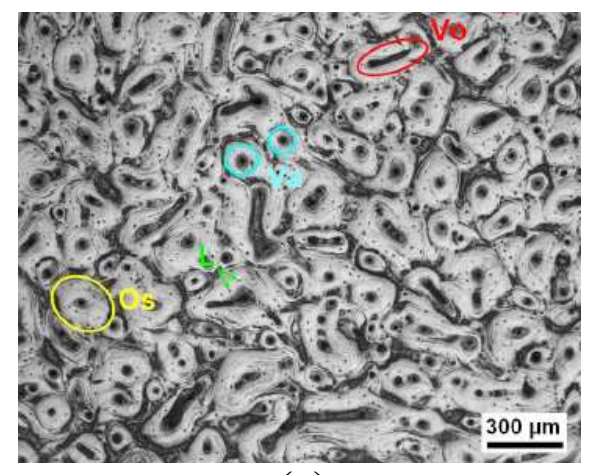

(a)

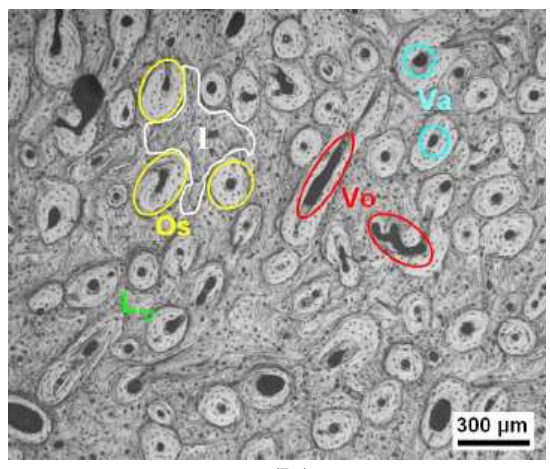

(b)

Figure 1. Optical micrographs of compact bone from (a) elk antler and (b) bovine femur (Os, osteons; Va, vascular channels; Vo, Volkmann canals; L, lacuna; I: interstitial bone). 
Primary osteons are generally smaller, irregular in shape, and do not have surrounding cement lines. High density of vascular channels which leads to accelerated growth rate can be observed. Bovine femur, on the other hand, consists of secondary osteons embedded in the interstitial bone. Secondary osteons result from bone modeling, and have a more rounded, uniform shape compared to primary osteons. Secondary osteons are surrounded by cement lines, which are considered as a weak path for fracture. The hypermineralized cement line plays an important role in the fracture of bone by deflecting the propagation of microcracks $[4,14,16]$.

Table I. Fracture toughness results for elk antler and bovine femur in different testing conditions.

\begin{tabular}{|c|c|}
\hline Sample & Fracture Toughness $K_{I c}\left(\mathrm{MPa} \cdot \mathrm{m}^{1 / 2}\right)$ \\
\hline Elk Antler Transverse (Dry) & 7.92 \\
\hline Elk Antler Transverse (Wet) & 10.31 \\
\hline Elk Antler Longitudinal (Dry) & 1.82 \\
\hline Elk Antler Longitudinal (Wet) & 3.06 \\
\hline Bovine Femur Transverse (Dry) & 3.92 \\
\hline Bovine Femur Transverse (Wet) & 6.35 \\
\hline Bovine Femur Longitudinal (Dry) & 1.81 \\
\hline Bovine Femur Longitudinal (Wet) & 2.12 \\
\hline
\end{tabular}

The fracture toughness results for elk antler and bovine femur in different orientations and hydration conditions are summarized in Table I. Fracture toughness values in the transverse orientation are 2-4 times higher than that in the longitudinal orientation and increase with the degree of hydration for both antler and bovine femur. The effect of orientation on fracture toughness is more significant than the effect of degree of hydration. The fracture toughness of antler is $\sim 50 \%$ higher than that of bovine femur. The highest fracture toughness value is obtained from the hydrated antler in the transverse orientation, which reached $10.31 \mathrm{MPa} \cdot \mathrm{m}^{1 / 2}$ while the lowest fracture toughness value is that measured from dry bovine femur in the longitudinal orientation, which is $1.81 \mathrm{MPa} \cdot \mathrm{m}^{1 / 2}$. The fracture toughness results for bovine femur in hydrated condition are consistent with previously reported values $\left(5.7 \mathrm{MPa} \cdot \mathrm{m}^{1 / 2}\right.$ in the transverse orientation [11] and 2.1-2.9 $\mathrm{MPa} \cdot \mathrm{m}^{1 / 2}$ in the longitudinal orientation [11]).

SEM micrographs of representative crack propagation for antler samples fractured in the longitudinal and transverse orientations after bending tests are shown in Fig. 2(a) and (b), respectively. In the transverse orientation, cracks tend to deflect away from the original extension direction as encounters the osteons and propagate along internal interfaces, causing delamination. Deflections of $\sim 90^{\circ}$ can be observed in Fig. 2(a). Crack deflection is also observed in bovine femur samples. In the longitudinal orientation, cracks propagate linearly along the osteons, as shown in Fig. 2(b). In both orientations, uncracked ligament bridging which is the main toughening mechanism in bone is observed. Microcracks initiate ahead of the main propagating crack, resulting in the formation of uncracked ligament bridges. Other toughening 
mechanisms, such as collage fiber bridging and microcrack formation around main crack, are also observed $[16,18]$.

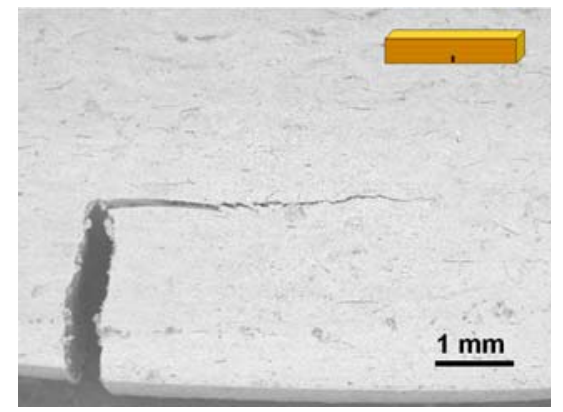

(a)

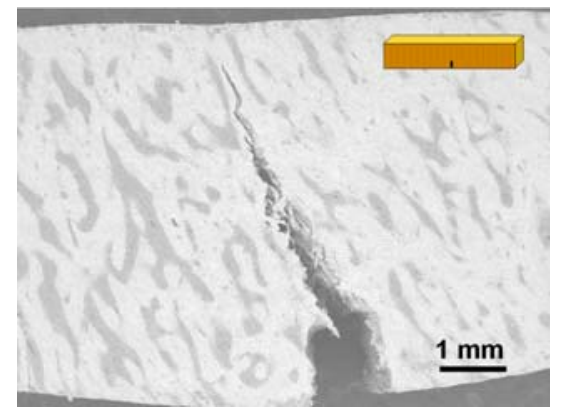

(b)

Figure 2. SEM micrographs showing typical antler samples fractured in the (a) transverse and (b) longitudinal orientations after bending.

Fracture surfaces of the antler and bovine femur samples after bending tests in dry conditions are shown in Fig. 3(a)-(d). The fracture surface of antler is very uneven and fibrous, indicating a ductile failure, as shown in Fig. 3(a) and (b). Fig. 3(a) shows the presence of transverse cracks and delamination around osteons in the transverse orientation. In the longitudinal orientation (Fig. 3(b)), separation between lamellae and fibrous nature of fracture surface are observed. The fracture surface of bovine femur, in contrast, appears very flat and smooth, indicating a brittle failure, as shown in Fig. 3(c) and (d). Delamination around osteons is also seen in bovine femur (Fig. 3(c)). The relatively flat region between secondary osteons corresponds to interstitial bone, which has higher degree of mineralization and brittle mechanical property. Fracture surface of bovine femur in the longitudinal orientation is very smooth and similar to the cleavage fracture in brittle materials (Fig. 3(d)). Cracks propagate through the weak path of cement line and lead to brittle failure.

The high fracture toughness has been attributed to the relatively low mineral content and the microstructure of antlers [6]. Both antler and bovine femur derive their toughness by uncracked ligament and collagen fiber bridging, crack deflection, and microcrack formation. However, the cracks formed in antler follow a much more tortuous route, resulting in rougher fracture surface compared with bone. Another toughening mechanism is that antler consists mainly of primary osteons which has no cement lines and interstitial bone, which are considered as the weak path for fracture. 


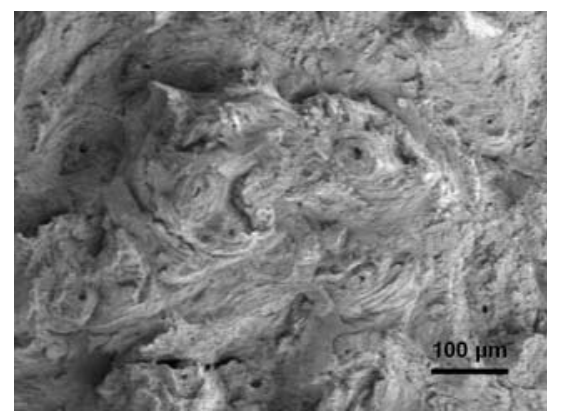

(a)

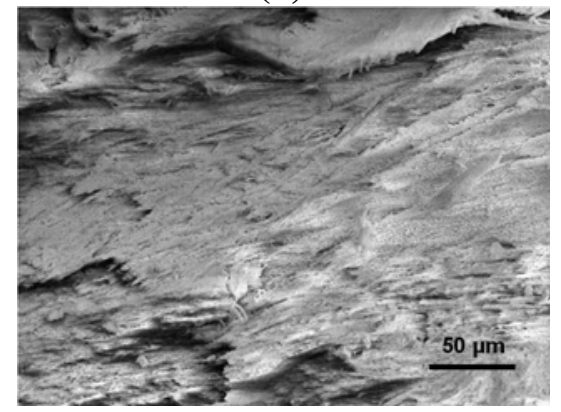

(b)

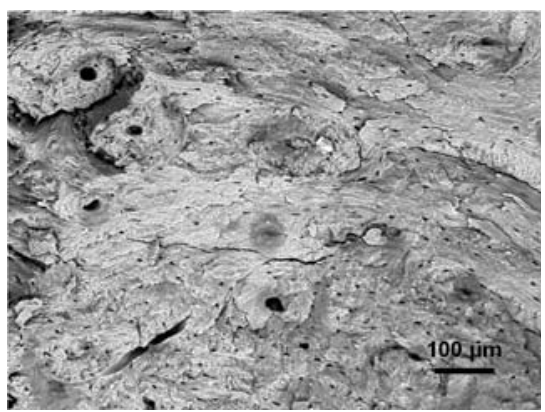

(c)

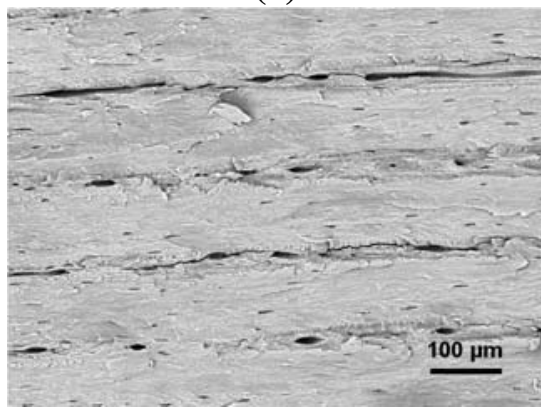

(d)

Figure 3. SEM micrographs of fracture surfaces after quasi-static bending tests in dry condition: (a) antler (transverse orientation), (b) antler (longitudinal orientation), (c) bovine femur (transverse orientation), and (d) bovine femur (longitudinal orientation).

\section{CONCLUSIONS}

In this study, we report the fracture toughness of North American elk (Cervus elaphus canadensis) antler and bovine femur in different orientations and hydration conditions. Fracture toughness in the transverse orientation is much higher than that in the longitudinal orientation due to the crack deflection and increased with degree of hydration. The fracture toughness of antler is $\sim 50 \%$ higher than that of bovine femur which is attributed to the lower mineral content and microstructure of antler. Toughening mechanisms, including crack deflection by osteons, uncracked ligament bridging, and microcracks formation, are observed in both antler and bovine femur samples.

\section{ACKNOWLEDGMENTS}

The authors would like to acknowledge Dr. Damon Toroin, Prof. Paul Price (Division of Biology, UCSD) and Prof. John Skedros (University of Utah) for helpful discussions and comments. Thanks go to students Chieuduong Nguyen, Ideen Sadr and Ali Rayatparvar who prepared samples and made preliminary measurements. Prof. Marc A. Meyers is especially thanked for his valuable insight, enthusiasm and support of this project. This research is funded by the National Science Foundation, Division of Materials Research, Biomaterials Program (DMR 0510138). 


\section{REFERENCES}

1. J. Henshaw, Nature 231, 469 (1971).

2. D.I. Chapman, Mam Review 5, 121 (1975).

3. J.D. Currey, J Biomech 12, 313 (1979).

4. J.G. Skedros, P. Durand, R.D. Bloebaum, J Bone Miner Res 10 (Suppl 1), 441 (1995).

5. J.D. Currey, Philos Trans R Roc Lond B 304, 509 (1984).

6. P. Zioupos, J.D. Currey, A.J Sedman, Med Eng Phys 16, 203 (1994).

7. A.C. Kitchener, "Fighting and the mechanical design of horns and antlers," Biomechanics in animal behaviour, ed. P. Domenici and R.W. Blake (Oxford 2000).

8. R.W. Blob, J,M, Snelgrove, J Morphol 267, 1075 (2006).

9. T. Landete-Castillejos, J.D. Currey, J.A. Estevez, E. Gaspar-López, A. Garcia, L. Gallego, Bone 41, 794 (2007).

10. P.-Y. Chen, A.G. Stokes, J. McKittrick, Acta Biomater (2008) in press.

11. D.M. Robertson, D. Robertson, C.R. Barret, J Biomech 11, 359 (1978).

12. W. Bonfield, M.D. Grynpas, R.J. Young, J Biomech 11, 473 (1978).

13. D. Vashishth, K.E. Tanner, W. Bonfield, J Biomech 33, 1169 (2000).

14. Y.N. Yeni, T.L. Norman, J Biomed Mater Res 51, 504 (2000).

15. P. Lucksanambool, W.A.J. Higgs, R.J.E.D. Higgs, M.W. Swain, Biomaterials 22, 3127 (2001).

16. R.K. Nalla, J.H. Kinney, R.O.Ritchie, Nature Materials 2, 164 (2003).

17. D. Vashishth, J Biomech 37, 943 (2004).

18. R.K. Nalla, J.J Kruzic, J.H. Kinney, R.O.Ritchie, Biomaterials 26, 217 (2005).

19. R.R. Adharapurapu, F. Jiang, K.S. Vecchio, Mater Sci Eng C 26, 1325 (2006).

20. ASTM C1421-01b. "Standard test methods for determination of fracture toughness of advanced ceramics," In: Annual Book of ASTM Standards vol 15.01 (PA, ASTM 2006). 